\title{
Sülfametiyazol-2,2'-Bipiridin Tuzunun Yapısal ve Spektral İncelenmesi: Deneysel ve Moleküler Modelleme Çalışması
}

\author{
Filiz ÖZTÜRK ${ }^{1 *}$, Tuğba AYCAN ${ }^{2}$, Ahmet Hilmi ÇON $^{3}$ \\ ${ }^{1}$ Ondokuz Mayıs Üniversitesi, Karadeniz İleri Teknoloji Araştırma ve Uygulama Merkezi, Samsun \\ ${ }^{2}$ Sinop Üniversitesi, Fizik Bölümü, Samsun \\ ${ }^{3}$ Ondokuz Mayıs Üniversitesi, Glda Mühendisliği Bölümü, Samsun \\ (ORCID: 0000-0002-0493-0446) (ORCID: 0000-0002-5313-7807) (ORCID: 0000-0002-1225-0133)
}

\begin{abstract}
Öz
Bu çalışmada sülfametiyazol-2,2'-bipiridin tuzunun sentezi, spektroskopik özellikleri (IR, UV-Vis ve termal) açıklanmaktadır. Birim hücrenin asimetrik biriminde, bir sülfametiyazol, bir 2,2'-bipiridin içermektedir. Karakterizasyon için tek kristal X-ışını kırınımı tekniği kullanılmıştır. 296 K' de tek kristal X-ışını kırınımı sonucuna göre $\mathrm{P} 2{ }_{1} / \mathrm{n}$ monoklinik uzay grubunda $\mathrm{a}=8.658$ (3) $\AA, \mathrm{b}=24.686$ (6) $\AA$, $\mathrm{c}=9.927$ (4) $\AA, \alpha=90^{\circ}, \beta=$ $103.61(3)^{\circ}, \gamma=90^{\circ}$ ve $Z=4$ olarak kristallendiği görülmüştür. Molekülün FT-IR ve UV-Vis spektroskopileri teorik ve deneysel olarak karşılaştırılmıştır. Teorik hesaplamalar ve optimize edilmiş geometrik parametrelerin tümü, yoğunluk fonksiyonel teorisi (DFT), B3LYP hibrit yöntemi 6-31G (d,p) baz seti kullanılarak hesaplanmıştır. TGA ile termal özellikler incelenmiştir. Kompleksin Staphylococcus aureus, Bacillus subtilis, Escherichia coli, Pseudomonas aeruginosa, Candida albicans ve Aspergillus flavus'a karşı antimikrobiyal çalışmaları yapılmıştır. Optimize edilmiş kompleks, 5J9B, 5BMM, 5HTG, 1ZUV, 4F0V ve 4YNU'ya yerleştirilerek biyolojik aktivitesi teorik olarak incelenmiştir.
\end{abstract}

Anahtar kelimeler: Sülfametiyazol, X-1şını kristal yapısı, Spektral Analiz, Modelleme çalışmaları, Antibakteriyel özellik.

\section{Investigation of structural and spectral of Sulfamethiazole-2,2'-Bipyridine Salt: Experimental and molecular modeling study}

\begin{abstract}
The present study describes the synthesis, spectroscopic properties of 2,2'-Bipyridine Salt of Sulfamethiazole. The asymmetrical part of the unit cell contains one sulfamethiazole, one 2,2'-Bipyridine. The techniques used for the characterization have been single crystal X-ray diffraction. The single crystal X-ray diffraction analysis at $296 \mathrm{~K}$ crystallizes in the monoclinic space group $\mathrm{P} 21 / \mathrm{n}$ with $\mathrm{a}=8.658(3) \AA, \mathrm{b}=24.686(6) \AA, \mathrm{c}=9.927(7) \AA, \alpha=90^{\circ}, \beta$ $=103.61(3)^{\circ}, \gamma=90^{\circ}$ and $Z=4$. FT-IR and UV-Vis spectroscopies of the molecule were compared theoretically and experimentally. All of theoretical calculations and optimized geometric parameters have been calculated by using density functional theory (DFT) with hybrid method B3LYP by 6-31G(d,p) basis set. Thermal properties have been investigated with TGA. The antimicrobial study was performed against Staphylococcus aureus, Bacillus subtilis, Escherichia coli, Pseudomonas aeruginosa, Candida albicans and Aspergillus flavus. The optimized complex is docked to the 5J9B, 5BMM, 5HTG, 1ZUV, 4F0V and 4YNU and the biological activity was also investigated theoretically.
\end{abstract}

Keywords: Sulfamethiazole, X-ray crystal structure, Spectral Analysis, Modelling Studies, Antibacterial property.

\section{Giriş}

Sülfonilamid ve sülfonamid türevlerine sahip gruplar yapısal olarak $-\mathrm{SO}_{2} \mathrm{NH}-\mathrm{k} 1 \mathrm{sm}$ ında değişiklik oluşturulmadan farklı fonksiyonel grupların değişimi yoluyla çok çeşitli farmakolojik aktiviteler

*Sorumlu yazar: filiz.ozturk@omu.edu.tr

Geliş Tarihi: 25.07.2019, Kabul Tarihi: 22.03.2020 
sergileyebildiği bilinmektedir [1,2]. Farmakolojik etkinliklerinden dolayı ise tedavi amaçlı olarak kullanılan önemli bir ilaç sınıfı olmaya devam etmektedir. Antibakteriyel sülfonamidler [3], diğer ilaçlar ile birlikte veya tek başlarına kemoterapide kullanılmaktadır [4]. Çinko enzim karbonik anhidrazı (CA, EC 4.2.1.1) inhibe eden sülfonamidler diüretik, antiglokom veya antiepileptik gibi birçok uygulamaya sahip olmaları nedeniyle, sülfonamidler tedavi sürecinde önemli bir rol oynamaya devam etmektedir [57].

Sülfametiyazol [4-amino-N-(5-metil-1,3,4-tiadiazol-2-yl) benzensülfonamid; Hsmtz], sülfonamid grubu ilaçların arasında en önemlilerinden biridir. Fonksiyonel dispepsi hastalarında, gastrik boşalmanın değerlendirilmesinde kontrast madde içeren kapsüller olarak kullanılmıştır [8]. Sülfonamid grubuna bağlı sübstitüentin bazik bir grup içerdiği sülfa ilaçları tautomerizm gösterebilir [9]. Protonun sülfonamid azot atomuna bağlı olduğunda tautomer, amino veya amido tautomeri olarak adlandırılırken, protonun tiyazol halkasına bağlı olduğunda tautomer, imino veya imido tautomeri olarak adlandırılır (Şekil 1) [10].

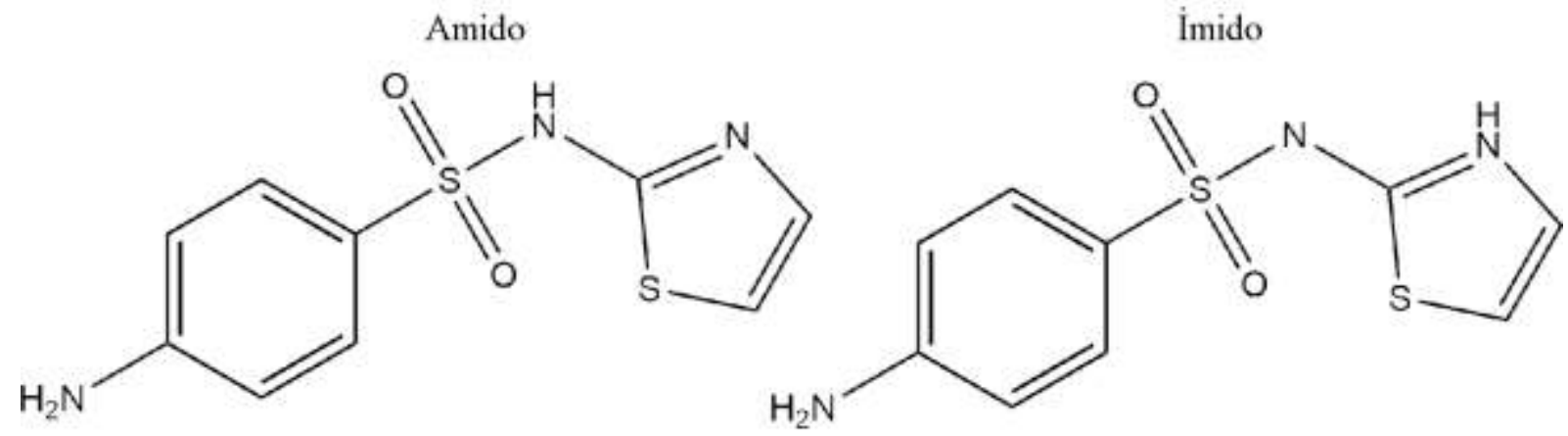

Şekil 1. 4-amino-N-(5-metil-1,3,4-tiadiazol-2-yl)sulfanilamid (sülfametiyazol)

Sülfa grubu ilaç molekülündeki kuvvetli hidrojen bağlanma işlevleri (iki donör: amin $\mathrm{NH}_{2}$ ve imin $\mathrm{NH}$; beş alıc1: iki sülfonil $\mathrm{O}$ atomu, tiyazolidin $\mathrm{N}$ ve $\mathrm{S}$ ve imidin $\mathrm{N}$ ), konformer ortaklarla birlikte ko-kristaller oluşturma kabiliyetine sahiptir. İlaçların biyofarmasötik özelliklerinin birlikte kristalleştirme ile geliştirilebileceği bildirilmiştir [11]. Farmasötik kristallerin daha düşük çözünme hızına sahip olması kristalin biyolojik açıdan etkinliğini artırır. Sülfa grubu ilaçlar, molekülündeki hidrojen bağlanan grupların varlığından dolayı ko-kristal formunda kristalleşmiştir.

Çalışmada ilk olarak sülfametiyazolün (Hsmtz), 2,2'-bipiridin (bipy) ile sentezlenmiştir. Elde edilen tuz kristallerin yapısal (XRD) ve spektral (IR ve UV-Vis) analizleri yapılmıştır. 6-31G(d,p) Baz seti kullanılarak B3LYP Hibrit metodu ile DFT kullanılarak geometrik parametreler optimize edilerek, teorik hesaplaması yapılmıştır. TG, DTG ve TGA eğrileri incelenerek termik analiz sonuçları elde edilmiştir. Antibakteriyel çalışmada ise ko-kristalin Staphylococcus aureus, Bacillus subtilis, Escherichia coli ve Pseudomonas aeruginosa bakterileri ile Candida albicans ve Aspergillus flavus mantarlarına karşı etkisi incelenmiştr. Buna ilaveten optimize edilen kompleks Protein Data Bank'tan (http://www.rcsb.org/pdb/home/home.do) alınan 5J9B, 1ZUV, 5BMM, 4F0V, 5HTG ve 4YNU ID kodlu proteinlere yerleştirilmiştir. Proteinin aktif bölgeleri ile kompleks hidrojen bağları ve zayıf etkileşimler yaparak, biyolojik aktivitesi teorik olarak incelenmiştir.

\section{Materyal ve Metot}

\subsection{Kompleksin Hazırlanması}

Sülfametiyazolün $(2 \mathrm{mmol}, 0.506 \mathrm{~g})$ sulu-metanol çözeltisi $(20 \mathrm{~mL}) \mathrm{NaOH}$ ile nötrleştirildi. 2,2'bipiridinin $(2 \mathrm{mmol}, 20 \mathrm{~mL})$ metanol çözeltisi karıştırılarak bu bileşiklerin sulu-metanol çözeltilerine ilave edildi ve son çözelti oda sıcaklığında bekletildi. Yaklaşık dört hafta sonra, renksiz, iyi şekillendirilmiş tek kristaller elde edildi. X-1şını difraksiyon çalışmaları için uygun ölçülerde iyi geliştirilmiş tek kristaller seçildi. Elementel analiz sonuçları; $\mathrm{C}_{22} \mathrm{H}_{35} \mathrm{CuN}_{9} \mathrm{O}_{7} \mathrm{~S}_{4}$; Hesaplanan: $\mathrm{C}, \% 53,50$; H, \%4,25; N, \%19,70; S, \% 15,03. Bulunan: C, \%58,07; H, \%5,07; N, \%17,84; S, \%11,50. 


\subsection{Genel Metotlar}

Orta Doğu Teknik Üniversitesi, merkez laboratuvarında element analizleri (C, H, N, S) yapılmıştır. IR spektrumu, Bruker Vertex $80 \mathrm{~V}$ FT-IR spektrometresi ile kaydedilmiştir. Örnekler KBr tekniği kullanılarak hazırlanmıştır. TG eğrisi, HITACHI-SII 7300 termal analizör ile azot atmosferinde $10 \mathrm{~K}$ $\min ^{-1}$ lik bir 1sıtma hızında ve platin kaplar kullanılarak $25-1000{ }^{\circ} \mathrm{C}^{\prime}$ lik bir sıcaklık aralığında kaydedilmiştir. Oda sıcaklığında, DMF ve etanol (\%50+\%50) çözeltisindeki UV-Görünür spektrumu 190 ila $800 \mathrm{~nm}$ arasında Evolution 220 UV-Vis spektrometresi ile kaydedilmiştir.

\subsection{X-ışını Kristalografisi}

Uygun tek kristal, bir cam fibere monte edilmiştir ve veri toplama, $\operatorname{MoK}_{\alpha}$ radyasyonu $(\lambda=0.71073 \AA)$ kullanılarak bir STOE IPDS(II) görüntü plakası dedektörü üzerinde gerçekleştirilmiştir. Veri toplama: Stoe X-AREA, hücre iyileştirme: Stoe X-AREA ve veri azaltma: Stoe X-RED kullanılmıştır [12]. Yapı, SIR-97 [13] kullanılarak doğrudan yöntemlerle çözüldü ve anizotropik yer değiştirme parametreleri, hidrojen olmayan atomlara, $\mathrm{F}^{2}$ ye bağlı olarak tam matrisli en küçük kareler arıtımı SHELXL-2016 [14] kullanılarak uygulanmıştır. Kristal yapının detayları Tablo l'de verilmiştir.

Tablo 1. Kompleksin kristal veri, veri toplama ve yapı arıtım parametreleri.

\begin{tabular}{|c|c|}
\hline Formül & $\mathrm{C}_{19} \mathrm{H}_{18} \mathrm{~N}_{6} \mathrm{O}_{2} \mathrm{~S}_{2}$ \\
\hline Moleküler ağırlığı $\left(\mathrm{g} \cdot \mathrm{mol}^{-1}\right)$ & 426.51 \\
\hline Kristal sistem & Monoklinik \\
\hline Uzay grubu & $P 2_{1} / \mathrm{n}$ \\
\hline Kristal rengi & Yeşil \\
\hline Kristal boyutu (mm) & $0.76 \times 0.50 \times 0.07$ \\
\hline Sicaklık (K) & 296 \\
\hline $\mathrm{a}, \mathrm{b}, \mathrm{c}(\AA)$ & $8.658(3), 24.686(6), 9.927$ (4) \\
\hline$\alpha, \beta, \gamma\left({ }^{\circ}\right)$ & $90,103.61(3), 90$ \\
\hline $\mathrm{V}\left(\AA^{3}\right)$ & $2062.2(12)$ \\
\hline $\mathrm{Z}$ & 4 \\
\hline$\lambda\left(\mathrm{Mo} \mathrm{K}_{\alpha}\right)(\AA)$ & 0.71073 \\
\hline$\mu\left(\mathrm{mm}^{-1}\right)$ & 0.29 \\
\hline$D_{\text {hes }}\left(\mathrm{g} \cdot \mathrm{cm}^{-3}\right)$ & 1.374 \\
\hline $\mathrm{F}(000)$ & 888 \\
\hline Data toplama $\theta$ aralığ $\left({ }^{\circ}\right)$ & $1.7-27.3$ \\
\hline Ölçülen yansımalar & 15407 \\
\hline Bağımsız yansımalar & $4285 \mathrm{i}$ \\
\hline $\mathrm{R}_{1}, \mathrm{wR}_{2}$ & $0.040,0.091$ \\
\hline S & 0.79 \\
\hline $\mathrm{R}_{\mathrm{int}}$ & 0.075 \\
\hline$\Delta \rho_{\text {maks }}, \Delta \rho_{\min }\left(\mathrm{e} \AA^{-3}\right)$ & $0.20,-0.24$ \\
\hline
\end{tabular}

\subsection{Antimikrobiyal Duyarlılık Testleri}

Ko-kristalin ve ligandın, Staphylococcus aureus ATCC 33862 (Gram pozitif), Bacillus subtilis NRRLB 209 (Gram pozitif), Escherichia coli ATCC 25922 (Gram negatif), Pseudomonas aeruginosa ATCC 27853 (Gram negatif), Candida albicans ATCC 10131 ve Aspergillus flavus MAM 200682 indikatör mikroorganizmalarına karşı antimikrobiyal aktivitesi, Ulusal Klinik Laboratuar Standartları Komitesi (NCCLS) önerilerine $(2002,2006)$ göre, mikro seyreltme tekniği (96 kuyucuklu mikroplaka tekniği) kullanılarak minimum inhibe edici konsantrasyonlar (MIC) olarak belirlenmiştir [15,16]. Bu analizde, çoğaltma ortamı olarak bakteri suşları için Mueller-Hinton Broth (Merck); maya suşu için RPMI 1640 broth (Merck) ve küf suşu sporlarını elde etmek için de Potato Dextrose Agar (Merck) besiyerleri kullanılmıştır. Antimikrobiyel aktivitesi test edilecek kompleks ve ligandı $1 \mu \mathrm{g} \mathrm{mL}^{-1}$ ile $512 \mu \mathrm{g} \mathrm{mL}^{-1}$ 
konsantrasyon arasında içerecek şekilde iki seri halinde ortamlar hazırlanmış ve 96 kuyucuklu mikroplakanın kuyucuklarına $100 \mu \mathrm{L}$ hacimlerde ilave edilmiştir.

Kuyucuklara aşılamak için bakterilerin 18 saatlik, mayanın 24 saatlik kültürleri ile küf sporlarından $0.5 \mathrm{Mc}$ Farland standardına eşdeğer yoğunluğa sahip süspansiyonlar hazırlanmış ve mikroplaka kuyucuklarındaki ortamlara bakteriler için $5 \times 10^{5} \mathrm{CFU} \mathrm{mL}^{-1}$, mayalar için $0.5 \times 10^{3}$ ila $2.5 \times 10^{3} \mathrm{CFU} \mathrm{mL}{ }^{-1}$ son konsantrasyon olacak şekilde aşılanmıştır. Daha sonra mikroplakalar, bakteriler için $35^{\circ} \mathrm{C}$ 'de 20 saat, maya için $25^{\circ} \mathrm{C}$ 'de 48 saat, küf için de $25^{\circ} \mathrm{C}$ 'de $72-96$ saat inkübe edilmiştir. İnkübasyon sonucu en düşük MIC değerini belirlemek için gelişme varlığı bakteri ve mayalarda spektrofotometrik ölçüm, küflerde gözle kontrol edilerek saptanmıştır.

\subsection{Moleküler Modelleme Çalışması}

Yoğunluk fonksiyonel teorisi (DFT) hesaplamaları Gaussian-09 yazılımı kullanılarak yapıldı [15]. Kompleksin minimum enerji moleküler geometrisi, B3LYP hibrit metodu kullanılarak hesaplandi. Geometrik optimizasyon 6-31G(d,p) baz setinde yapıldı. Moleküler yerleştirme (MD) yapısal moleküler biyoloji ve bilgisayar destekli ilaç tasarımında önemli bir yöntemdir. Staphylococcus aureus, Bacillus subtilis, Escherichia coli, Pseudomonas aeruginosa, Candida albicans ve Aspergillus flavus kristal yapıları sirasıyla Protein Veri Bankası'ndan indirildi (Sirasıyla; PDB ID: 5J9B, 1ZUV, 5BMM, 4F0V, 5HTG ve 4YNU http://www.rcsb.org./pdb). Moleküler yerleştirme çalışmaları AutoDock Tool (ADT) v1.5.6 ve AutoDock Vina yerleştirme yazılımı ile gerçekleştirildi [16]. AutoDock Tool yazılımı ile protein rezidülerine polar hidrojen atomları eklendi. Kompleks üzerindeki her bir atom tipi için önceden hesaplanmış atomik afinite 1zgarası haritası AUTOGRID ile oluşturuldu. (x x $(\AA))$ 1zgara kutusu $1 \AA$ aralıklıdır. Kompleks ve proteinler arasındaki etkileşimler Discovery Studio Visualizer yazılımı ile gerçekleştirildi [17].

\section{Bulgular ve Tartışma}

\subsection{X-ışını Çalışması ve Optimize Geometri}

XRD sonuçlarına göre, kompleks birim hücre başına dört molekül $(Z=4)$ ile $P 2_{1} /$ n uzay grubuna sahiptir. Monoklinik kristal sistemine sahip kompleksin hücre boyutları şu şekildedir; a $=8.658$ (3) $\AA$, $\mathrm{b}=24.686$ (6) $\AA, \mathrm{c}=9.927$ (4) $\AA$ ve $\beta=103.61$ (3) ${ }^{\circ}$. Kompleksin asimetrik biriminde bir sülfametiyazol molekülü ve bir 2,2' bipiridin molekülü içerir (Şekil 2). Kristal oluşumunda amino formunda bulunan sülfametiyazolün sülfonamido bölümündeki protonu, tiyadiazol halkasındaki azot atomuna bağlanarak imido formunda kompleks oluşumunun sağlandığı görülmektedir (Şekil 1).

$\mathrm{X}$-1şını analizi sonucu göz önüne alınarak, molekülün bağ uzunlukları incelendiğinde N2-S1

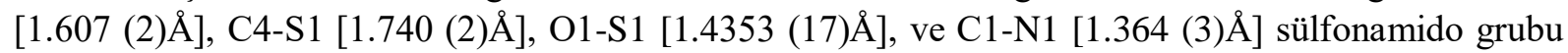
bağ uzunlukları literatürle karşılaştırıldığında kısaldığı, O2-S1 [1.4466 (18) $\AA$ ] bağının ise uzadığ

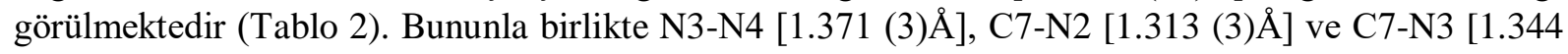
(3) ̊ tiyadiazol grubu bağ uzunluklarında ise neredeyse hiçbir değişim olmadığı görülmektedir [18]. Sülfonamido grubunun bağ uzunluklarındaki bu değişikliklerin kaynağının, kristal paketlenmede $S$ ve $\mathrm{O}$ atomlarının yapmış olduğu hidrojen bağı etkileşimlerine bağlanabilir. Ayrıca trans formda kristallenen 2,2'-bipiridinin bağ uzunlukları literatür ile karşılaştırıldığında sadece C15-C16 [1.371 (3) ̊̊ bağ uzunluğunun uzadığı diğer bağ uzunluklarında ise neredeyse hiçbir değişimin olmadığ görülmektedir [19]. 


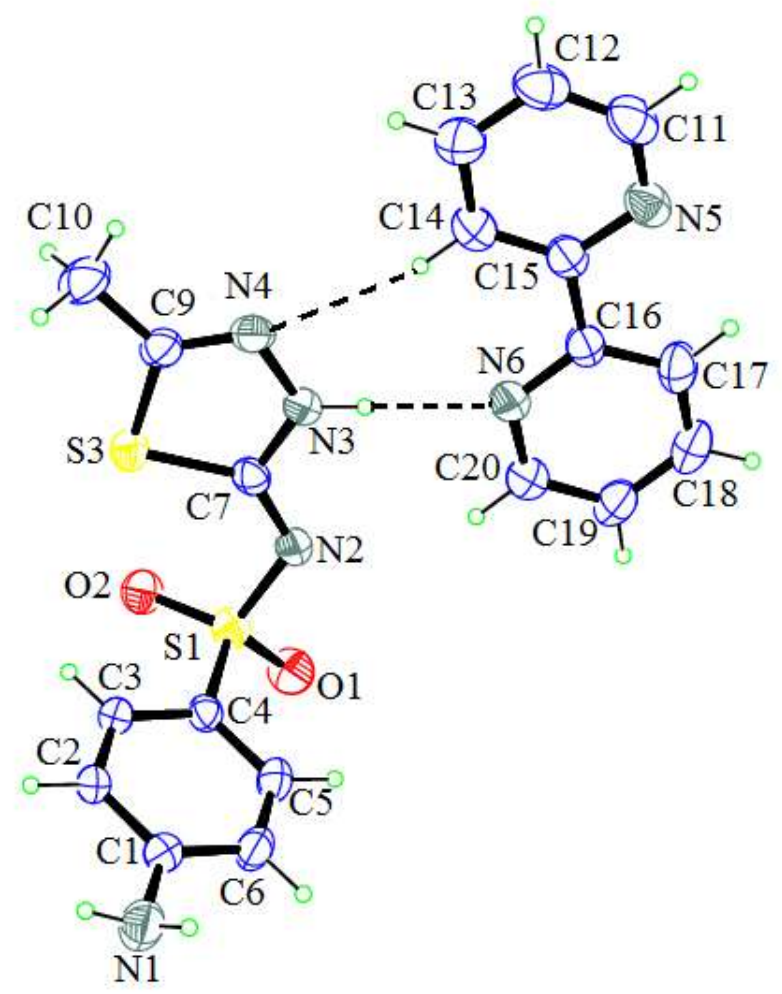

Şekil 2. Kompleksin moleküler yapısı

Tablo 2. Kompleksin deneysel ve hesaplamalı bağ uzunlukları, bağ açıları ve literatür karşıllkları

\begin{tabular}{lllll}
\hline & Kompleks & {$[18]$} & {$[19]$} & DFT/6-31G(d,p) \\
\cline { 1 - 1 } \multicolumn{1}{l}{ Bağ uzunluklar1 $(\AA)$} & & & & \\
N3-N4 & $1.371(3)$ & $1.372(2)$ & - & 1.365 \\
C7-N2 & $1.313(3)$ & $1.318(2)$ & - & 1.299 \\
N2-N3 & $1.344(3)$ & $1.334(2)$ & - & 1.360 \\
C4-S1 & $1.607(2)$ & $1.6142(14)$ & - & 1.673 \\
O1-S1 & $1.740(2)$ & $1.7544(17)$ & - & 1.781 \\
O2-S1 & $1.435(2)$ & $1.4387(15)$ & - & 1.465 \\
C1-N1 & $1.447(2)$ & $1.4396(14)$ & - & 1.479 \\
C15-C16 & $1.364(3)$ & $1.387(2)$ & - & 1.386 \\
N5-C15 & $1.485(4)$ & - & $1.471(4)$ & 1.492 \\
C15-C14 & $1.346(3)$ & - & $1.350(3)$ & 1.349 \\
C16-N6 & $1.370(4)$ & - & $1.372(4)$ & 1.402 \\
C16-C17 & $1.343(3)$ & - & $1.347(3)$ & 1.347 \\
Bağ aç1lar1 ( $)$ & $1.387(4)$ & - & $1.383(4)$ & 1.402 \\
C4-S1-N2 & & & & \\
N3-C7-S3 & 107.07 & - & - & 102.61 \\
N2-C7-N3 & $107.88(18)$ & $107.97(13)$ & - & 106.99 \\
C7-N2-S1 & $120.80(20)$ & $120.79(15)$ & - & 121.24 \\
O1-S1-O2 & $119.27(16)$ & $120.34(12)$ & - & 120.69 \\
N1-C1-C6 & $117.11(12)$ & $117.11(12)$ & - & 119.91 \\
C14-C15-C16 & $120.70(20)$ & $120.36(17)$ & - & 120.55 \\
N5-C15-C16 & $122.50(20)$ & - & $124.0(2)$ & 122.30 \\
C17-C16-C15 & $115.80(20)$ & - & $114.9(2)$ & 115.65 \\
N6-C16-C15 & $120.80(30)$ & - & $123.5(3)$ & 119.63 \\
\hline
\end{tabular}




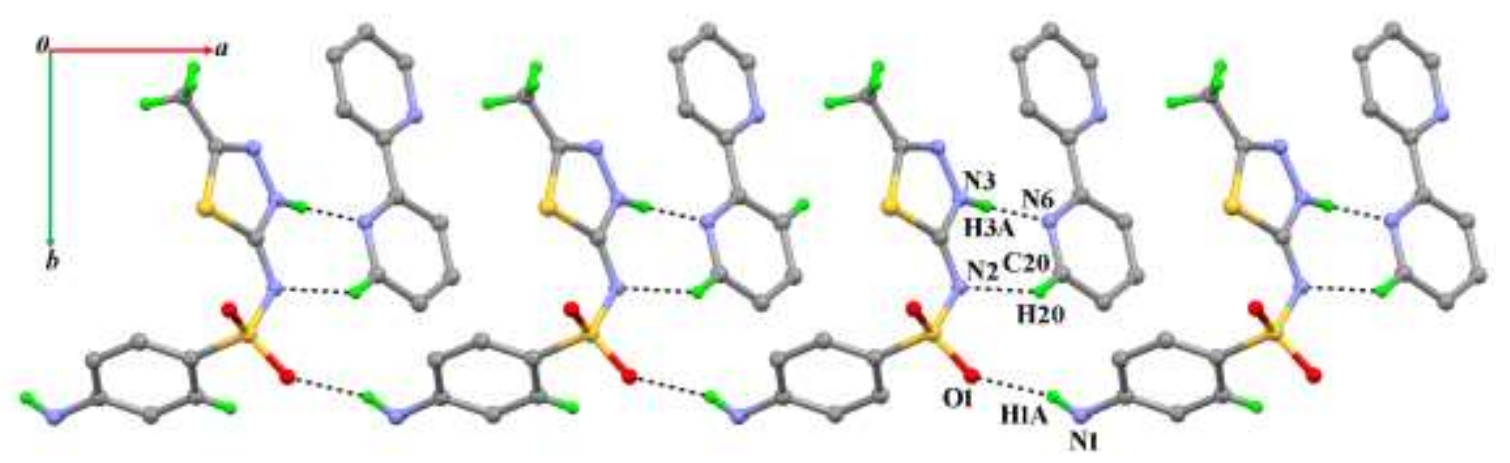

Şekil 3. [100] doğrultusu boyunca ilerleyen C(8) zincirleri ile oluşan bir boyutlu ağ (Hidrojen bağı yapmayan hidrojen atomları çıkarılmıştır)

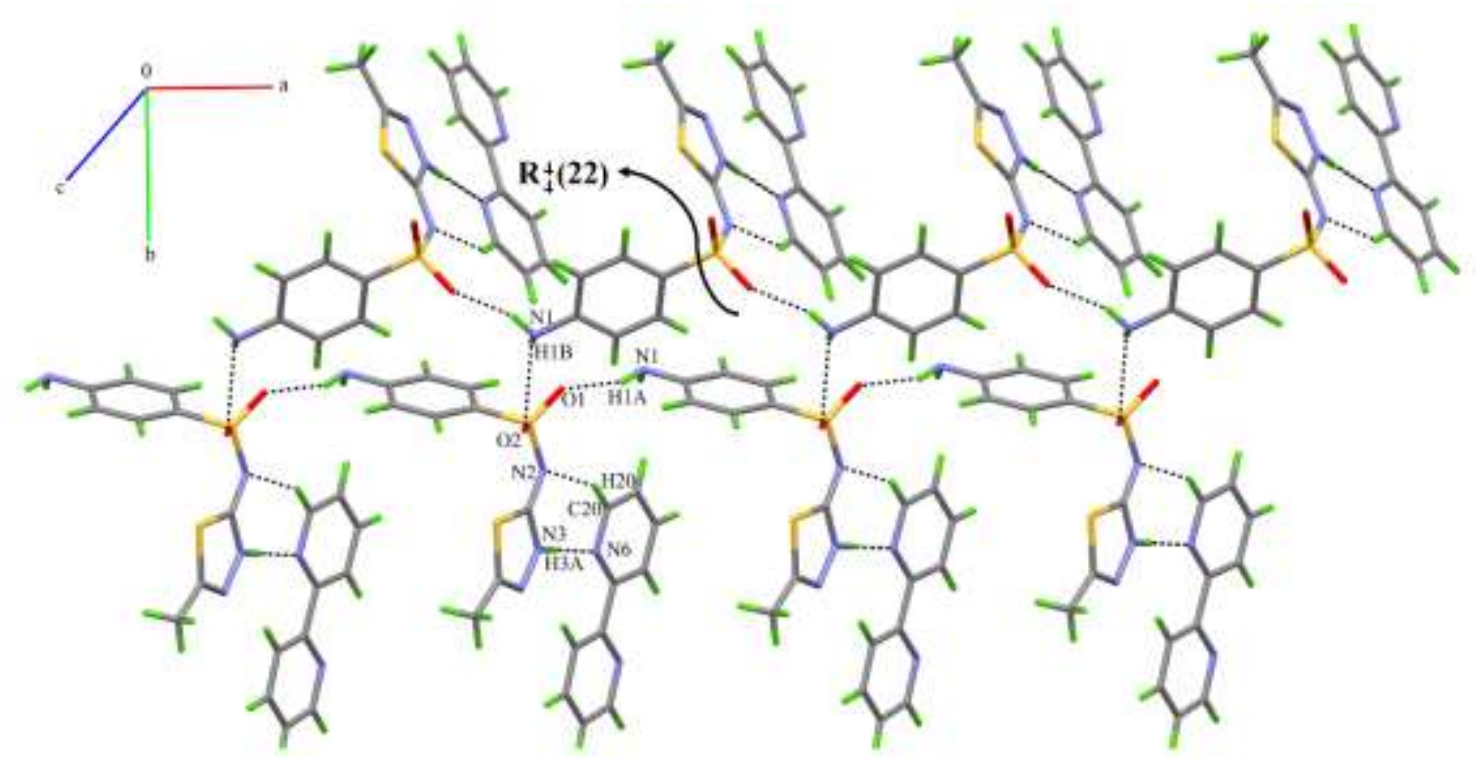

Şekil 4. 1D zincirlerin N1-H1B $\cdots \mathrm{O} 2$ ve N1-H1A $\cdots \mathrm{O} 1$ hidrojen bağları ile oluşan (110) düzlemindeki $R_{4}^{4}(22)$ halkaları 


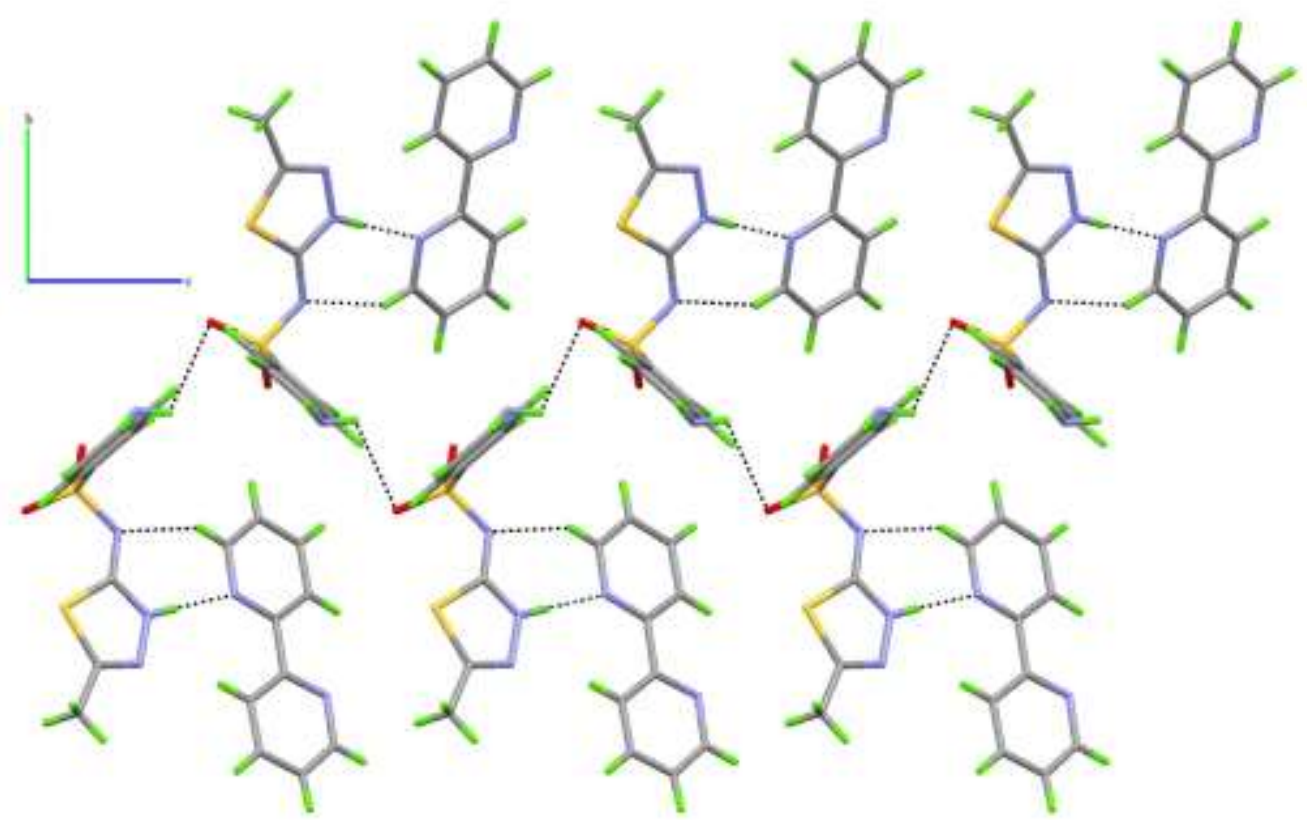

Şekil 5. a-ekseninden bakıldığında N1-H1B $\cdots$ O $2^{\mathrm{ii}}$ hidrojen bağları ile oluşan C(8) zincirlerinin [001] doğrultusunda ilerleyerek oluşturduğu üç boyutlu yapı

Kompleksin kristal paketlenmesi, molekül içi ve moleküller arası etkileşimler $(\mathrm{C}-\mathrm{H} \cdots \mathrm{N}, \mathrm{N}-\mathrm{H}$ $\cdots \mathrm{O}, \mathrm{N}-\mathrm{H} \cdots \mathrm{S}$ ve $\mathrm{N}-\mathrm{H} \cdots \mathrm{N}$ ) ile sağlanmaktadır (Tablo 3). Asimetrik birimde $\mathrm{N}-\mathrm{H} \cdots \mathrm{N}$ and $\mathrm{C}-\mathrm{H} \cdots \mathrm{N}$ molekül içi hidrojen bağları sülfametiyazol ile 2,2'-bipiridini birbirine bağlamaktadır (Şekil 2). Sülfonamid grubunun azot atomu ile bipiridinin piridil halkasındaki karbon atomu arasında C20$\mathrm{H} 2 \cdots \mathrm{N} 2$ molekül içi hidrojen bağı ve tiyadiazol halkasının azot atomu ile bipiridinin piridil halkasının azot atomu arasında ise N3-H3A $\cdots \mathrm{N} 2$ molekül içi hidrojen bağ bağları iki sülfametiyazol ligandlarını birbirlerine bağlamaktadır. Bu hidrojen bağları [100] doğrultusunda $\mathrm{C}(8)$ zincirleri bir boyutlu ağı oluşturmuştur (Şekil 3). Bu bir boyutlu ağlar N1$\mathrm{H} 1 \mathrm{~B} \cdots \mathrm{O} 2{ }^{\text {ii }}$ hidrojen bağları ile bağlanarak $R_{4}^{4}(22)$ halkalarını meydana getirmiş (halka merkezleri $1+\mathrm{n}_{1}$, $1 / 4,3 / 4 ; \mathrm{n}_{1}, 0.34$ ve onun katları şeklindedir) ve (110) düzleminde iki boyutlu düzlem oluşturmuş̧ur (Şekil 4). Bunun dışında aynı N1-H1B $\cdots \mathrm{O} 2^{\mathrm{ii}}$ hidrojen bağları ile oluşan $\mathrm{C}(8)$ zincirleri [001] doğrultusunda ilerleyerek üç boyutlu yapıyı oluşturmaktadır (Şekil 5).

Tablo 3. Kompleksin hidrojen bağ geometrisi

\begin{tabular}{lllll}
\hline $\mathrm{D}-\mathrm{H} \cdots \mathrm{A}$ & $\mathrm{D}-\mathrm{H}$ & $\mathrm{H} \cdots \mathrm{A}$ & $\mathrm{D} \cdots \mathrm{A}$ & $\mathrm{D}-\mathrm{H} \cdots \mathrm{A}$ \\
\hline $\mathrm{C} 20-\mathrm{H} 20 \cdots \mathrm{N} 2$ & 0.93 & 2.60 & $3.420(4)$ & 148 \\
$\mathrm{~N} 1-\mathrm{H} 1 \mathrm{~A} \cdots \mathrm{O} 1^{\mathrm{i}}$ & 0.86 & 2.12 & $2.943(3)$ & 160 \\
$\mathrm{~N} 1-\mathrm{H} 1 \mathrm{~B} \cdots \mathrm{O} 2^{\mathrm{ii}}$ & 0.86 & 2.60 & $3.018(3)$ & 111 \\
$\mathrm{~N} 1-\mathrm{H} 1 \mathrm{~B} \cdots \mathrm{S} 1^{\mathrm{ii}}$ & 0.86 & 2.99 & $3.688(3)$ & 139 \\
$\mathrm{~N} 3-\mathrm{H} 3 \mathrm{~A} \cdot \mathrm{N} 6$ & 0.86 & 2.02 & $2.877(3)$ & 177 \\
\hline
\end{tabular}

Symmetry codes: (i) $\mathrm{x}-1, \mathrm{y}, \mathrm{z}$; (ii) $\mathrm{x}-1 / 2,-\mathrm{y}+1 / 2$

Gözlemlenen ve hesaplanan kompleksin bağ uzunlukları, bağ açıları Tablo 2'de listelenmiştir. Geometrik parametrelerin kuramsal değerleri deneysel değerler ile karşılaştırıldığında bağ uzunluklarında en fazla sapma N2-S1 bağ uzunluğunda $0.066 \AA ̊$ olarak görülmektedir. X-1şını sonuçlarına göre kompleksin C7-N2-S1 bağları elektronları ortaklaşa kullandığından N-S uzunluğu hesaplamalı sonuca göre daha kısadır [20]. Bağ uzunluğundaki bu sapmalardan dolayı bağ açısındaki en büyük sapmalar da C4-S1-N2 ve O1-S1-O2 bağ aç1larında sırasıyla $4.46^{\circ}$ ve $2.80^{\circ}$ olduğu görülmektedir. Literatürle karşılaştırıldığında en büyük sapmaların yine N-S bağ uzunluklarında ve CS-N bağ açılarında olduğu görülmüştür [21]. Geometrik parametrelerin teorik değerleri, küçük 
farklılıklara rağmen neredeyse deneysel değerlerle uyumludur (Şekil 6). Bu farklılıklar, gaz fazındaki yok sayılan moleküler etkileşimlerden kaynaklanmaktadır. Deneysel ve teorik geometrik parametreler arasındaki uyum incelendiğinde, r.m.s.d 0.1032 'dir. Bu değer, optimize edilmiş yapı ile deneysel yapının birbirleriyle oldukça uyumlu olduğunu göstermiştir.

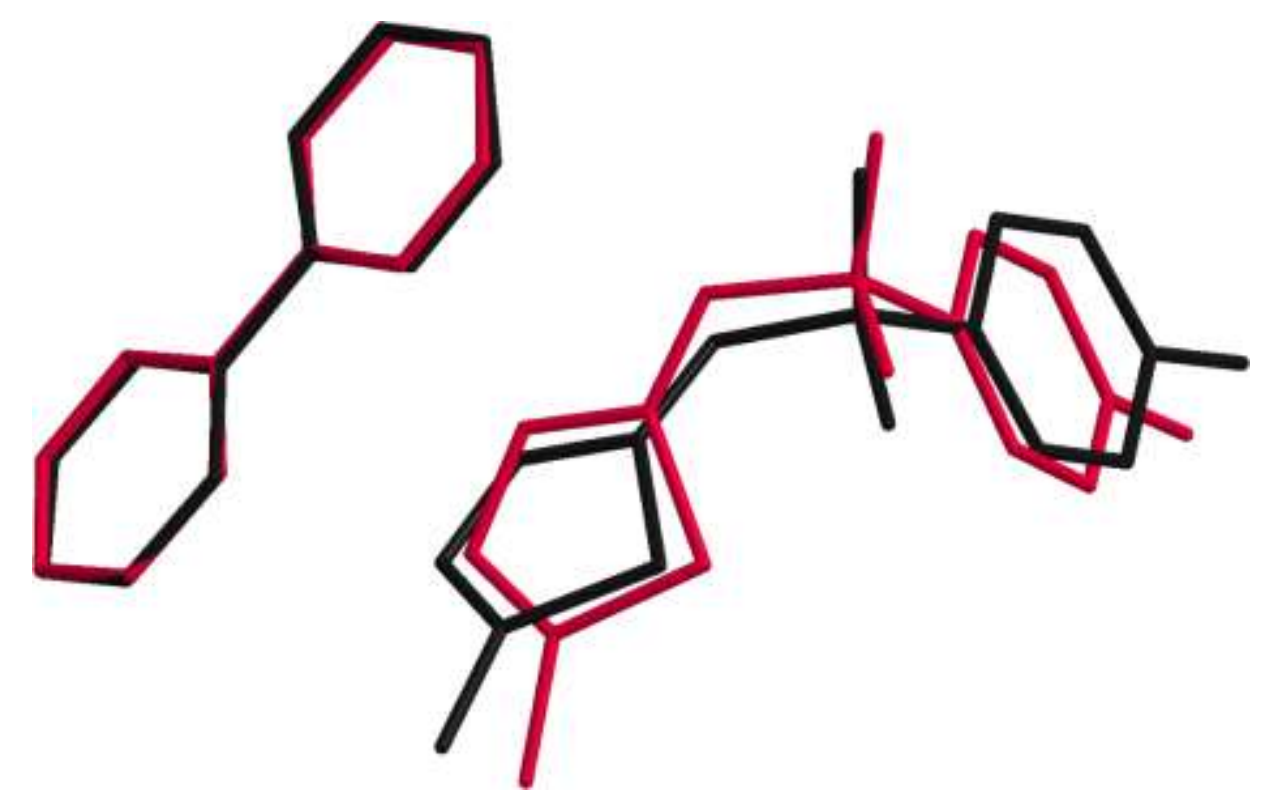

Şekil 6. Kompleks için optimize edilmiş (siyah) ve deneysel (kırmızı) yapısının üst üste binmiş görüntüsü

\subsection{FT-IR Spektroskopisi}

Kompleksin infrared spektrumda deneysel ve teorik bantlar ile serbest Hsmtz ve literatür değerleri karşılaştırmalı olarak Tablo 4'de listelenmiştir. Normal modlar için hesaplama sonucunda elde edilen frekansların deneysel değerlerden biraz farklı oldukları görülmektedir. Deneysel olarak elde edilen spektrumun katı faz numunesi kullanılarak kaydedilmiş olması, teorik hesaplamanın ise izole edilmiş, gaz faz molekülü kullanılarak yapılmış olması bu küçük farklılığın nedeni açıklamaktadır. Bunun için ampirik ölçeklendirme faktörleri (titreşim frekansı skala faktörü) dikkate alınarak yapılan teorik titreşim frekanslarını hesaplanması yapıldı [22]. Yapılan hesaplamalar sonucunda deneysel ile teorik veriler arasındaki titreşim frekansı skala faktörü literatüre uygun olarak kullanıldığı görülmektedir [23]. Kompleksin ve sülfametiyazolün deneysel FT-IR spektrumu Şekil 7' de verilmiştir.

Serbest sülfametiyazol ligandının IR spektrumunda, N-H gerilim titreşimine karşılık gelen bantlar $3444 \mathrm{~cm}^{-1}$ ve $3357 \mathrm{~cm}^{-1}$ ' de (sırasıyla asimetrik ve simetrik titreşimler) olduğu ve literatür ile uyumlu olduğu görülmektedir [24]. Kompleksin IR spektrumunun yüksek enerji bölgesindeki $3498 \mathrm{~cm}^{-}$ ${ }^{1}$ ve $3400 \mathrm{~cm}^{-1}$ de bulunan absorbsiyon bantları, amino grubunun $v_{a s}\left(\mathrm{NH}_{2}\right)$ ve $v_{\mathrm{s}}\left(\mathrm{NH}_{2}\right)$ titreşimlerine karşılık gelir (Şekil 7). Kompleksin titreşim bantları, serbest ligandın titreşim bantlarına göre daha yüksek frekanslara kaydığı görülmektedir. Bu kaymanın nedeni büyük olasılıkla $\mathrm{NH}_{2}$ ve $\mathrm{SO}_{2}$ gruplarını içeren kompleksler arasındaki hidrojen bağ etkileşimlerinden kaynaklanmaktadır [25]. Hsmtz'nin N-H gerilme titreşimi ise imido formunda tiyadiazol halkasında $3254 \mathrm{~cm}^{-1}$, amido formunda sülfo grubunda $3242 \mathrm{~cm}^{-1}$, de iken kompleks oluşumu ile bu bantlar sırasıyla $3290 \mathrm{~cm}^{-1}$ ve $3248 \mathrm{~cm}^{-1}$, e kaymıştır. Amido-imido tautomeri özelliği gösteren Hsmtz ligandındaki imido pikindeki kayma bipy ligandı ile yapmış olduğu hidrojen bağından kaynaklandığı düşülmektedir. Sülfametiyazolün sülfonomido grubunun $\mathrm{SO}_{2}$ grubunun titreşim frekanslarını ise incelediğimizde $\mathrm{v}_{\mathrm{as}}\left(\mathrm{SO}_{2}\right)^{\prime}$ nin $1318 \mathrm{~cm}^{-1}$ ve $1307 \mathrm{~cm}^{-}$ 1' e daha düşük frekansa kayarken $\mathrm{v}_{\mathrm{s}}\left(\mathrm{SO}_{2}\right)$ 'nin ise $1190 \mathrm{~cm}^{-1}$ ve $1172 \mathrm{~cm}^{-1}$,e daha yüksek frekansa kaydığı gözlenmiştir. XRD sonuçlarındaki bağ uzunlarını ve kristal oluşumunda sülfametiyazolün imido formunda olduğu göz önüne alındığında uyumlu olduğu sonucuna varılmıştır. 


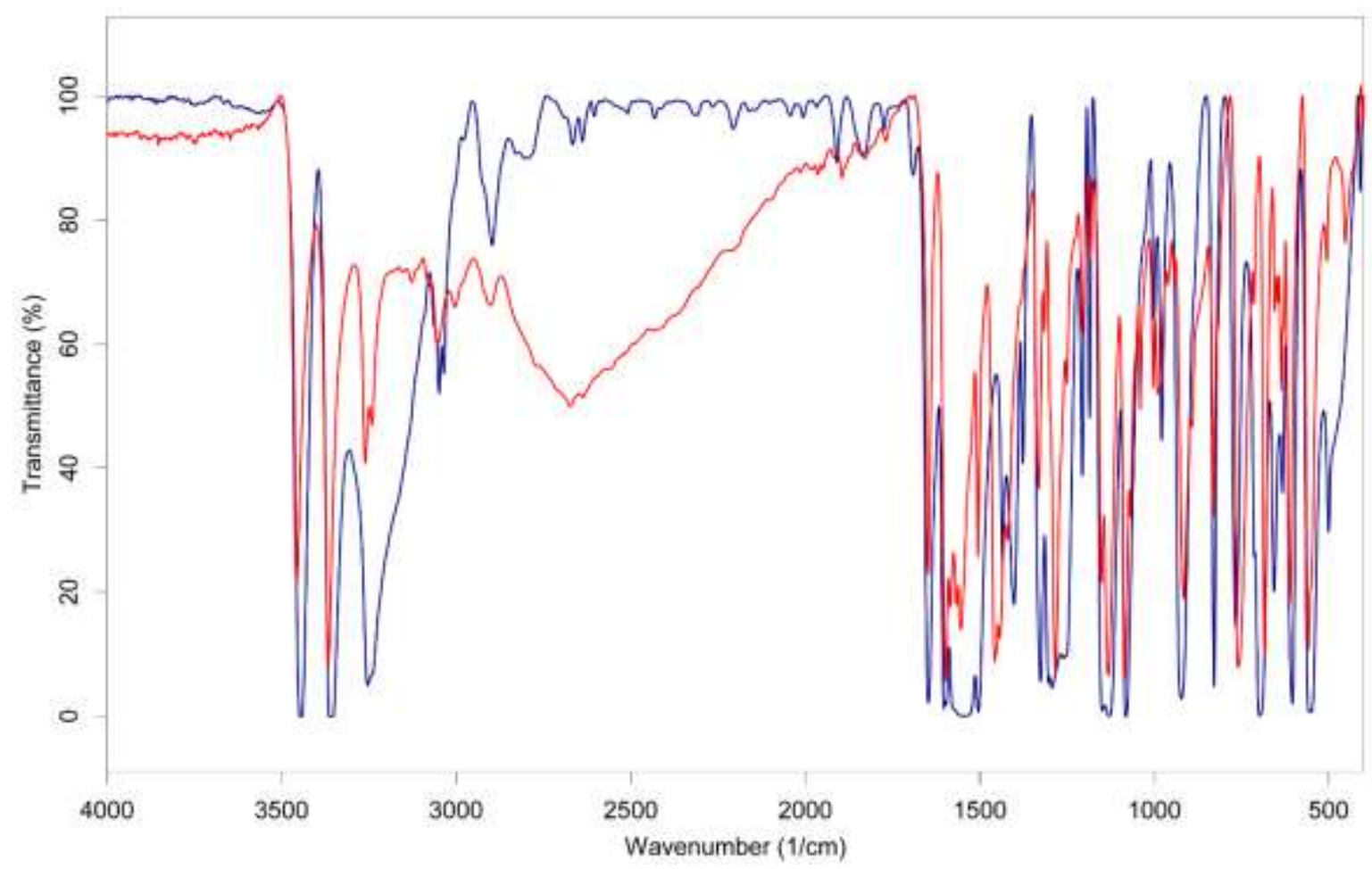

Şekil 7. Kompleksin deneysel IR spektrumu (kırmızı çizgi), sülfametiyazolün deneysel IR spektrumu (mavi çizgi)

Tablo 3. Deneysel olarak ölçülen ve kuramsal olarak hesaplanan kompleksin karşılaştırılmalı titreşim pikleri

\begin{tabular}{|c|c|c|c|c|}
\hline Assignments & SMTZ & Experimental IR with $\mathrm{KBr}$ & [26] & DFT/B3LYP/6-31G(d,p) \\
\hline$v_{\text {as }}\left(\mathrm{NH}_{2}\right)$ & $3444 \mathrm{vs}$ & 3498sgeniş & 3444 & 3505 \\
\hline$v_{s}\left(\mathrm{NH}_{2}\right)$ & $3357 \mathrm{vs}$ & $3400 \mathrm{~s}$ & 3359 & 3407 \\
\hline$v(\mathrm{NH})_{\text {imido }}$ & $3254 \mathrm{vs}$ & $3290 \mathrm{~s}$ & - & - \\
\hline$v(\mathrm{NH})_{\text {amido }}$ & $3242 v s$ & $3248 s$ & 3257 & 3257,3245 \\
\hline$v(\mathrm{CH})_{\text {bipy }}$ & - & $3139 w$ & - & \\
\hline$v(\mathrm{CH})_{\text {fenil }}+v(\mathrm{CH})_{\text {bipy }}$ & $3048 s, 3035 s$ & & - & $3223-3163$ \\
\hline$v\left(\mathrm{CH}_{3}\right)_{\mathrm{Hsmtz}}$ & $2897 \mathrm{~m}$ & $3083 \mathrm{~W}-28 / 0 \mathrm{~W}$ & 2917 & $3153-3052$ \\
\hline$\delta\left(\mathrm{NH}_{2}\right)_{\mathrm{Hsmtz}}$ & $1647 \mathrm{ws}$ & $1621 \mathrm{ws}$ & 1604 & \\
\hline$\delta(\mathrm{NH})_{\text {imido }}$ & - & $1588 \mathrm{~m}$ & & $1675-1653$ \\
\hline $\begin{array}{l}\text { Halka str.fenil } \\
\text { Halka str. }\end{array}$ & 1602ws, $1596 w s$ & $1575 \mathrm{~s}, 1561 \mathrm{~s}, 1532 \mathrm{sh}$ & - & 1652,1643 \\
\hline$v(\mathrm{C}-\mathrm{C})$ (bipy) & - & - & - & $1627-1615$ \\
\hline$\delta(\mathrm{CH})_{\text {fenil }}$ & 1504ws & $1514 w s$ & - & 1544 \\
\hline$\delta(\mathrm{NH})_{\text {amido }}$ & - & 1479 ws & - & 1536 \\
\hline$\delta(\mathrm{CH})_{\text {bipy }}$ & - & $1448 \mathrm{~m}$ & - & 1528,1504 \\
\hline$\delta_{\mathrm{as}}\left(\mathrm{CH}_{3}\right)_{\mathrm{Hsmtz}}$ & $1434 \mathrm{~m}$ & $1426 \mathrm{~m}$ & - & 1493,1488 \\
\hline$\delta(\mathrm{NH})_{\text {imido }}$ & $1400 \mathrm{~s}$ & $1385 \mathrm{sh}$ & - & 1485 \\
\hline$\gamma\left(\mathrm{NH}_{2}\right)_{\mathrm{Hsmtz}}$ & $1376 \mathrm{~s}$ & $1349 \mathrm{~s}$ & - & 1475 \\
\hline$v_{a s}\left(\mathrm{SO}_{2}\right)$ & 1326ws & $1318 \mathrm{ws}, 1307 \mathrm{ws}$ & 1326 & 1296 \\
\hline$\delta_{\mathrm{s}}\left(\mathrm{CH}_{3}\right)_{\mathrm{Hsmtz}}$ & $1303 \mathrm{~s}, 1292 \mathrm{~s}$ & $1297 \mathrm{sh}$ & - & 1426 \\
\hline$\gamma\left(\mathrm{NH}_{2}\right)_{\mathrm{Hsmtz}}$ & $1260 \mathrm{~s}, 1251 \mathrm{~s}$ & $1256 \mathrm{~s}$ & - & 1375 \\
\hline$\delta(\mathrm{CH})_{\text {bipy }}$ & - & $1236 \mathrm{~m}, 1230 \mathrm{~m}$ & - & 1356,1339 \\
\hline$\gamma(\mathrm{NH})_{\mathrm{Hsmtz}}$ & $1186 \mathrm{~s}$ & - & - & - \\
\hline$v_{s}\left(\mathrm{SO}_{2}\right)$ & $1149 \mathrm{~s}, 1127 \mathrm{~s}$ & $1190 \mathrm{~s} 1172 \mathrm{~s}$ & 1130 & 1077 \\
\hline$\delta(\mathrm{CN})_{\text {tiadiazol }}$ & - & 1080 & - & - \\
\hline$v(\mathrm{SN})$ & $921 \mathrm{~s}$ & $897 \mathrm{~s}$ & - & - \\
\hline
\end{tabular}




\subsection{Kimyasal Aktivitesi}

Kompleks için en yüksek enerjili dolu moleküler orbital (HOMO) ve en düşük enerjili boş moleküler

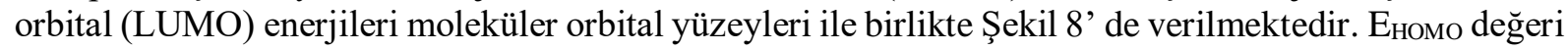
artarsa, bileşiğin reaktivitesi artarken, ELUMO değeri azalmasıyla bileşiğin biyolojik değeri artmaktadır. Buna göre molekülün reaktivitesinin eğilimi $\mathrm{E}_{\text {Bо §̦LUK }}$ değerinin azalmasıyla artar. Kimyasal sertlik ve yumuşaklık kuralına göre, yumuşak ve sert asitler sırasıyla yumuşak ve sert bazlara koordine olmayı tercih eder. Hücre ve enzim gibi yumuşak moleküllerin biyolojik reaktivitesi sert moleküllerinkinden daha yüksektir. Küçük $\chi$ veya yüksek CP molekül üzerine kolayca delokalize olan elektronu gösterir. Molekülün biyolojik reaktivitesi elektrofisilik değerin azalması veya nükleofisilik değerin artmasıyla artar. Biyolojik aktivite bileşiğin yüküyle ilgili olarak küresel yumuşaklık ve $\Delta_{\mathrm{MAX}}$ değerinin artması ile artar [26]. Tüm bunlar göz önüne alındığında Tablo 5' deki değerlere göre yeni sentezlenen kompleksin sülfametiyazol ve sülfatiyazol [27] ligandlarına göre daha çok biyolojik ve kimyasal aktiviteye sahip olduğunu göstermektedir. Optimize molekülün MEP haritası, en çok elektronegatif bölgeyi kırmızı renk ile gösterirken, elektropozitif bölge mavi renk ile gösterilir. Negatif potansiyel bölgeler, güçlü molekül içi ve moleküller arası hidrojen bağları nedeniyle O1 ve O2 atomları üzerindedir (Şekil 9). Tablo 3'deki hidrojen bağları incelendiğinde elektron alma özelliğinden dolayı amin grubu $\left(\mathrm{NH}_{2}\right)$ en koyu mavi renge sahiptir. Böylece MEP yüzeyi reaktif alanları göstermektedir.
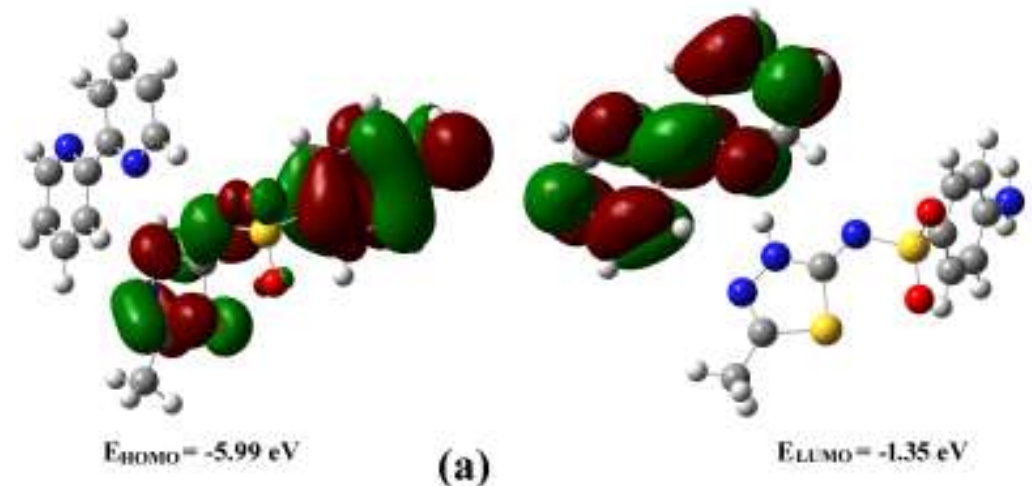

(a)

$$
\text { Eимо }=-1.35 \mathrm{eV}
$$

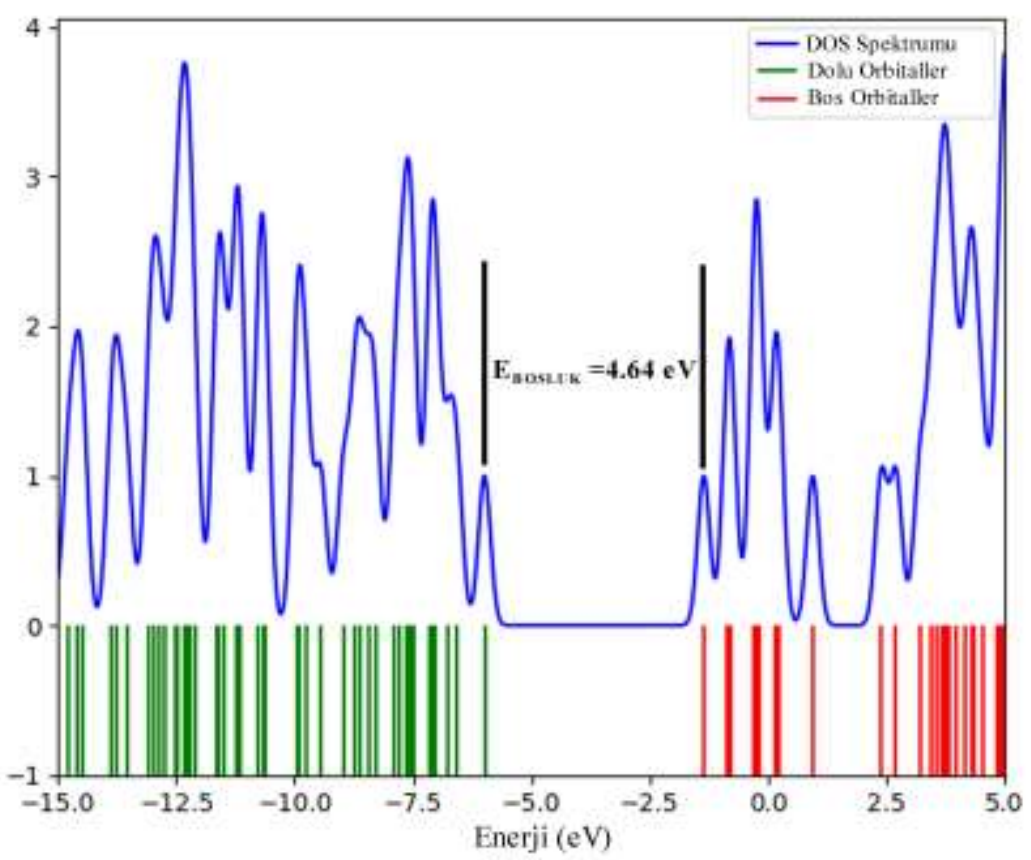

(b)

Şekil 8. Kompleksin (a) HOMO, LUMO değerleri için DFT/B3LYP yöntemi kullanılarak elde edilen enerji seviyeleri ve moleküler yörünge yüzeyleri (b) hesaplanan toplam yoğunluk durumu (TDOS) spektrumu 
Tablo 5. Kompleksin hesaplanan kuantum kimyasal tanımları

\begin{tabular}{|c|c|c|c|}
\hline DFT & Kompleks (eV) & Sülfametiyazol & Sülfatiyazol [27] \\
\hline $\mathrm{E}_{\text {HOMO }}{ }^{\mathrm{a}}$ & -5.99 & -5.83 & -5.97 \\
\hline $\mathrm{E}_{\text {LUMO }}{ }^{\mathrm{a}}$ & -1.35 & -0.77 & -0.90 \\
\hline $\mathrm{E}_{\mathrm{GAP}}{ }^{\mathrm{a}}$ & 4.64 & 5.06 & 5.07 \\
\hline $\mathrm{I}^{\mathrm{a}}$ & 5.99 & 5.83 & 5.97 \\
\hline $\mathrm{A}^{\mathrm{a}}$ & 1.35 & 0.77 & 0.90 \\
\hline$\eta^{\mathrm{a}}$ & 2.32 & 2.53 & 2.54 \\
\hline$\sigma^{\mathrm{b}}$ & 0.43 & 0.39 & 0.39 \\
\hline$\chi^{\mathrm{a}}$ & 3.67 & 3.30 & 3.44 \\
\hline $\mathrm{CP}^{\mathrm{a}}$ & -3.67 & -3.30 & -3.44 \\
\hline$\omega^{\mathrm{a}}$ & 2.90 & 2.15 & 2.33 \\
\hline $\mathrm{N}^{\mathrm{b}}$ & 0.34 & 0.46 & 0.43 \\
\hline$\Delta \mathrm{N}_{\mathrm{MAX}}$ & 1.58 & 1.30 & 1.35 \\
\hline $\mathrm{S}^{\mathrm{b}}$ & 0.22 & 0.19 & 0.20 \\
\hline
\end{tabular}

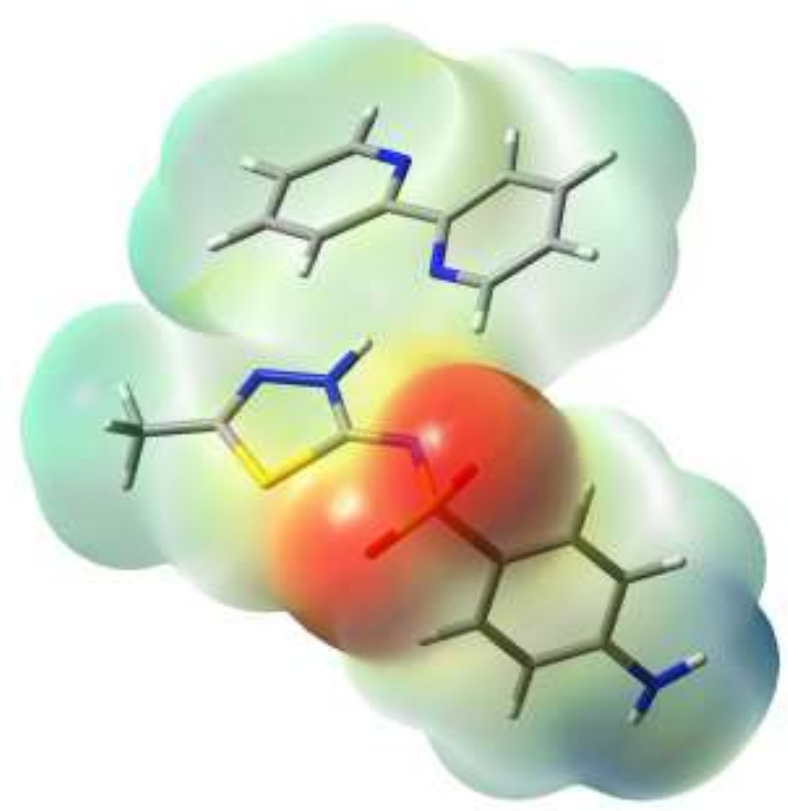

Şekil 9. Kompleksin DFT/B3LYP/6-31G (d,p) seviyesinde hesaplanan MEP yüzeyi

\subsection{Elektronik Absorbsiyon Spektroskopisi}

Kompleksin UV-Vis spektrumu DMF ve etanolde 190-800 nm aralığında kaydedildi. Ayrıca, enerji seviyeleri arasındaki geçişler TD-DFT metodu ile çalışılmıştır. UV-Vis absorbsiyon verileri GaussSum 3.0 yazılımı kullanılarak hesaplanmıştır [28]. $200 \mathrm{~nm}$ ve $290 \mathrm{~nm}$ arasında gözlenen bantlar piridin halkasındaki $\pi \rightarrow \pi^{*}$ geçişlerinden kaynaklanmaktadır. $\pi \rightarrow \pi^{*}$ geçişlerinin hesaplanan değerleri (264 nm ve $274 \mathrm{~nm}$ ) deneysel değerler $(208 \mathrm{~nm}, 212 \mathrm{~nm}$ ve $284 \mathrm{~nm}$ ) ile karşılaş̧ırıldığında sonuçlar birbirlerine çok yakın çıkmamıştır. Bu kayma çözücünün etkisinden kaynaklanıyor olabilir [29]. Kompleksin deneysel UV spektrumunda gözlenen $308 \mathrm{~nm}$ 'deki pik $\mathrm{n} \rightarrow \pi^{*}$ geçişinden kaynaklanmaktadır (hesaplanan $291 \mathrm{~nm}$ ). Deneysel UV spektrumda 540 nm'de ortaya çıkan pik görünür bölgededir. Kompleksi oluşturan ligandların her ikisi de renksiz olmasına rağmen tek kristal açık pembe renklidir. Bu nedenle 540 nm'de bir maksimum görülmüştür.

\subsection{Termal Analiz}

Kompleksinin termal analiz eğrisi Şekil 10' da verilmektedir. $55-210{ }^{\circ} \mathrm{C}$ sıcaklık aralığında kompleksin yapısında bulunan 2,2'-bipiridin endotermik olarak uzaklaşmaktadır. Bu basamakta \%36.0'lık bir kütle 
azalması meydana gelmektedir (DTG $\mathrm{DTaks}: 184{ }^{\circ} \mathrm{C}$; hes:\%36.6). Son basamakta ise $210-412{ }^{\circ} \mathrm{C}$ sicakl1k aralığında geriye kalan organik kalıntının yanması $293^{\circ} \mathrm{C}$ 'de endotermik olayla gerçekleşmektedir. $\mathrm{Bu}$ sıcaklıktan daha yüksek sıcaklıklara çıkıldığında bozunmanın devam ettiği görülmektedir. Bozunmalar sonucunda $1000{ }^{\circ} \mathrm{C}^{\prime}$ ye gelindiğinde $\% 21.0$ 'lik organik bir kalıntı kalmaktadır.

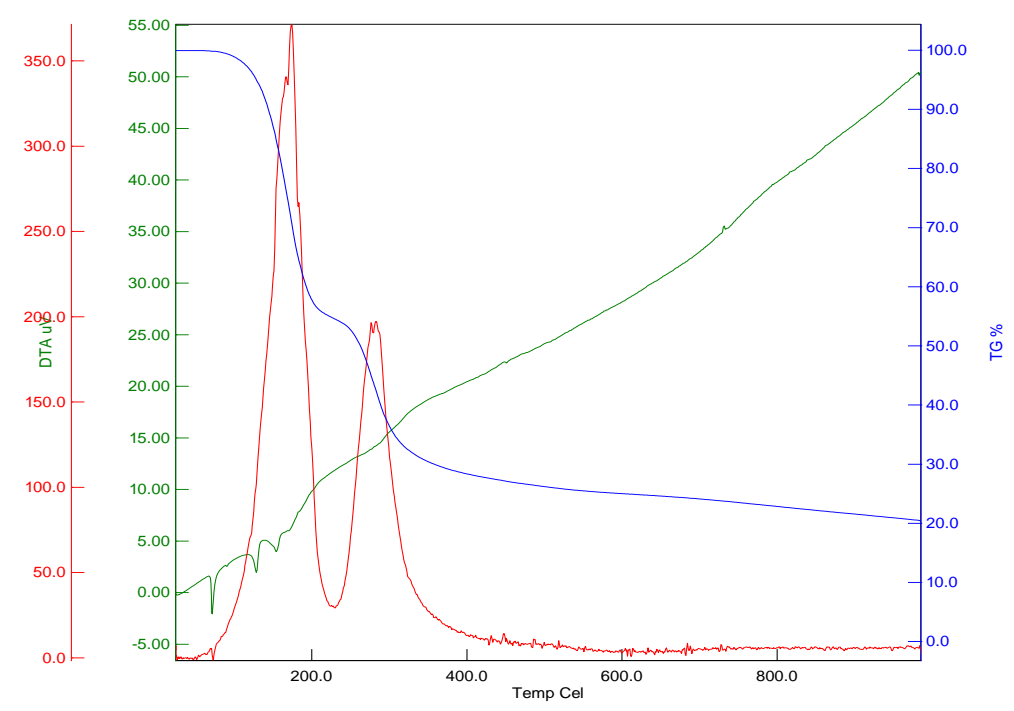

Şekil 10. Kompleksin termal analiz eğrisi

\subsection{Antimikrobiyal Analiz}

Sülfametiyazol, sülfonamid grubundan bir antibiyotiktir [30]. Bu çalışmada, sülfametiyazol ve yeni sentezlenen kompleksinin antimikrobiyal aktivite analizi iki Gram pozitif bakteri (Staphylococcus aureus ATCC 33862 ve Bacillus subtilis), iki Gram negatif bakteri (Pseudomonas aeruginosa ve Escherichia coli), bir maya (Candida albicans) ve bir küf(Aspergillus flavus) suşlarına karşı yapılmıştır. Kompleksin MIC değerlerinin Aspergillus flavus MAM 20068 için $64 \mu \mathrm{g} / \mathrm{mL}$ konsantrasyona ve Escherichia coli ATCC 25922 için de $128 \mu \mathrm{g} / \mathrm{mL}$ konsantrasyona düştüğü ve sülfametiyazolden daha yüksek etkinliğe sahip olduğu tespit edilmiştir (Tablo 6). Sentezlenen yeni kompleksin sülfametiyazole göre daha yüksek biyolojik ve kimyasal aktiviteye sahip olduğu görülmektedir. Antimikrobiyel aktivitesinde bir artış göstermesi beklenen bir sonuçtur.

Tablo 6. Kompleksin ve sülfametiyazolün MIC değerleri

\begin{tabular}{|c|c|c|c|c|c|c|}
\hline \multicolumn{7}{|c|}{ Mikroorganizmalar } \\
\hline \multirow[t]{2}{*}{ Bileşikler } & S. aureus & B. subtilis & P. aeruginosa & E. coli & C. albicans & A. flavus \\
\hline & \multicolumn{6}{|c|}{ MIC value $(\mu \mathrm{g} / \mathrm{mL})$} \\
\hline Sülfametiyazol & $>512$ & 1 & $<1$ & 256 & $<1$ & 128 \\
\hline Kompleks & $>512$ & 1 & $<1$ & 128 & $<1$ & 64 \\
\hline
\end{tabular}

Yeni sentezlenmiş kompleksin diğer indikatör mikroorganizmalara karşı sülfametiyazolden farklı bir MIC değeri vermemesi sonucu ise test için kullanılan etken maddelerin konsantrasyonlarından kaynaklanabilir. Çalışmada S. aureus'a karşı test edilen en yüksek konsantrasyonun $(512 \mu \mathrm{g} / \mathrm{mL})$ her iki bileşen için de etkisiz olması bir farklılık doğmamasına neden olmuştur. Daha yüksek değerlere çıkılması durumunda sülfametiyazol ile yeni kompleksin MIC değerinde bir farklılaşma beklenebilir. Ancak daha yüksek konsantrasyonlarda etki anlamlı bulunmadığ 1 için test edilmemiştir. Yine, Bacillus subtilis, Pseudomonas aeruginosa ve Candida albicans'a karşı etkinlikte de kompleks ile sülfametiyazolün benzer MIC değerine sahip olması, test edilen en düşük konsantrasyonun $(1 \mu \mathrm{g} / \mathrm{mL})$ her iki form için de etkin olması ve daha düşük konsantrasyonların da denenmemesinden kaynaklanmış olabilir. $\mathrm{Bu}$ mikroorganizmalar için daha düşük konsantrasyonların denenmesi durumunda MIC değerinde değişim meydana gelmesi olasıdır. 


\subsection{Moleküler Yerleştirme Çalışması}

Staphylococcus aerous, Escherichia coli, Candida Albicans, Bacillus Subtilis, Pseudomonas aeruginosa ve Aspergillus Flavus bakteri ve mayalarının sülfametiyazol-bipiridin ile etkileşimini anlamak ve etkileşim mekanizmasını açıklamak için moleküler yerleştirme çalışması yapıldı. Yerleştirme hesapları 5J9B, 5BMM, 5HTG, 1ZUV, 4F0V ve 4YNU protein modellerinde yapıldı. Analiz (Hsmtz-Bipy)'in, 5J9B etkileşiminde, ALA101, ALA97 ve ALA30'un aktif bölgelerde bulunan en temel rezidüler olduğunu göstermiştir. Benzer olarak, 5BMM ile etkileşiminde TYR511 ve LYS351'in aktif bölgelerinde, 5HTG ile etkileşiminde GLU115, ARG44, LYS45 ve ASP31' in aktif bölgelerinde, 1ZUW ile etkileşiminde GLU153 ve ARG45' in aktif bölgelerinde, 4F0V ile etkileşiminde VAL129 ve ASP134'in aktif bölgelerine ve son olarak 4YNU ile etkileşiminde sadece su moleküllerinde bulunan en temel rezidüler olduğunu göstermiştir. Kompleksin tüm proteinler ile baskın olarak hidrojen bağ1 yaptığını göstermiştir. Etkileşimleri içeren olası etkileşim modelleri ve temel rezidülerin yaptığ1 etkileşim türleri Tablo 7'de gösterilmiştir. İlaç çekirdeği $\mathrm{H}$ bağları ile bağlanma yerlerine bağlanan proteinler ile etkileşir. Hedef protein ile kompleks arasındaki etkileşimler Şekil 11'de gösterilmiştir.

Tablo 7. Kompleksin bahsedilen proteinlerle yaptığı etkileşim türleri ve etkileşim yaptı̆̆ı rezidüler

\begin{tabular}{|c|c|c|c|c|c|c|}
\hline $\begin{array}{l}\text { Ligand- } \\
\text { Protein } \\
\text { X:Kompleks }\end{array}$ & İsim & $\begin{array}{l}\text { Uzaklık } \\
(\AA)\end{array}$ & $\begin{array}{l}\text { Bağlanma } \\
\text { Tipi }\end{array}$ & $\begin{array}{l}\text { Proteinde } \\
\text { bağlanan site }\end{array}$ & $\begin{array}{l}\text { Liganda } \\
\text { bağlanan } \\
\text { site }\end{array}$ & $\begin{array}{l}\text { Proteine } \\
\text { bağlanma } \\
\text { Modu } \rightarrow \\
\text { Ligand }\end{array}$ \\
\hline $\mathrm{X}-5 \mathrm{~J} 9 \mathrm{~B}$ & $\begin{array}{l}\text { UNK0:H- } \\
\text { B:ALA101:O }\end{array}$ & 3.0208 & $\mathrm{CH} \cdots \mathrm{O}$ & B:ALA101:O & UNK0:H & $\begin{array}{l}\text { H-Donör } \rightarrow \mathrm{O}- \\
\text { Akseptör }\end{array}$ \\
\hline $\mathrm{X}-5 \mathrm{~J} 9 \mathrm{~B}$ & $\begin{array}{l}\text { UNK0:H- } \\
\text { A:ALA97:O }\end{array}$ & 2.8682 & $\mathrm{H}-\mathrm{Bağ} 1$ & A:ALA97:O & UNK0:H & $\begin{array}{l}\text { H-Donör } \rightarrow \mathrm{O}- \\
\text { Akseptör }\end{array}$ \\
\hline $\mathrm{X}-5 \mathrm{~J} 9 \mathrm{~B}$ & $\begin{array}{l}\text { A:ALA30:HN3- } \\
\text { UNK0:O }\end{array}$ & 2.2658 & H-Bağ 1 & A:ALA30:HN3 & UNK0:O & $\begin{array}{l}\text { HN3- } \\
\text { Donör } \rightarrow \mathrm{O}- \\
\text { Akseptör }\end{array}$ \\
\hline X-5BMM & $\begin{array}{l}\text { A:TYR511:HH- } \\
\text { UNK0:S }\end{array}$ & 2.9069 & $\mathrm{H}-\mathrm{Bağ} 1$ & A:TYR511:HH & UNK0:S & $\begin{array}{l}\text { H-Donör } \rightarrow \text { S- } \\
\text { Akseptör }\end{array}$ \\
\hline X-5BMM & $\begin{array}{l}\text { B:LYS351:HZ3- } \\
\text { UNK0:S }\end{array}$ & 2.2751 & H-Bağ & B:LYS351:HZ3 & UNK0:S & $\begin{array}{l}\text { H-Donör } \rightarrow \text { S- } \\
\text { Akseptör }\end{array}$ \\
\hline X-5HTG & $\begin{array}{l}\text { UNK0:H- } \\
\text { B:GLU115:OE1 }\end{array}$ & 2.4277 & $\mathrm{H}-\mathrm{Bağ} 1$ & B:GLU115:OE1 & UNK0:H & $\begin{array}{l}\text { H-Donör } \rightarrow \mathrm{O}- \\
\text { Akseptör }\end{array}$ \\
\hline X-5HTG & $\begin{array}{l}\text { B:ARG44:CD- } \\
\text { UNK0:O }\end{array}$ & 3.4199 & $\mathrm{CH}-\mathrm{Bağ} 1$ & B:ARG44:CD & UNK0:O & $\begin{array}{l}\text { H-Donör } \rightarrow \mathrm{O}- \\
\text { Akseptör }\end{array}$ \\
\hline X-5HTG & $\begin{array}{l}\text { B:LYS45:NZ- } \\
\text { UNK0 }\end{array}$ & 4.8595 & Pi-Katyon & B:LYS45:NZ & UNK0 & $\begin{array}{l}\text { N-Donör } \rightarrow \text { Pi- } \\
\text { Orbital }\end{array}$ \\
\hline X-5HTG & $\begin{array}{l}\text { B:ASP31:OD2- } \\
\text { UNK0 }\end{array}$ & 3.4933 & Pi-Anyon & B:ASP31:OD2 & UNK0 & $\begin{array}{l}\text { O-Donör } \rightarrow \text { Pi- } \\
\text { Orbital }\end{array}$ \\
\hline $\mathrm{X}-1 \mathrm{ZUV}$ & $\begin{array}{l}\text { UNK0:H- } \\
\text { A:GLU153:O }\end{array}$ & 2.4716 & H-Bağı & A:GLU153:O & UNK0:H & $\begin{array}{l}\text { H-Donör } \rightarrow \mathrm{O}- \\
\text { Akseptör }\end{array}$ \\
\hline X-1ZUV & $\begin{array}{l}\text { A:ARG45:NH2- } \\
\text { UNK0 }\end{array}$ & 4.0464 & Pi-Katyon & A:ARG45:NH2 & UNK0 & $\begin{array}{l}\text { N-Donör } \rightarrow \text { Pi- } \\
\text { Orbital }\end{array}$ \\
\hline $\mathrm{X}-1 \mathrm{ZUV}$ & $\begin{array}{l}\text { B:ARG45:NH1- } \\
\text { UNK0 }\end{array}$ & 3.4263 & Pi-Katyon & B:ARG45:NH1 & UNK0 & $\begin{array}{l}\text { N-Donör } \rightarrow \text { Pi- } \\
\text { Orbital }\end{array}$ \\
\hline $\mathrm{X}-4 \mathrm{~F} 0 \mathrm{~V}$ & $\begin{array}{l}\text { UNK0:H- } \\
\text { A:VAL129:O }\end{array}$ & 2.6975 & H-Bağ 1 & A:VAL129:O & UNK0:H & $\begin{array}{l}\text { H-Donör } \rightarrow \mathrm{O}- \\
\text { Akseptör }\end{array}$ \\
\hline $\mathrm{X}-4 \mathrm{FOV}$ & $\begin{array}{l}\text { A:ASP134:OD2- } \\
\text { UNK0 }\end{array}$ & 3.8316 & Pi-Anyon & A:ASP134:OD2 & UNK0 & $\begin{array}{l}\text { O-Donör } \rightarrow \text { Pi- } \\
\text { Orbital }\end{array}$ \\
\hline X-4YNU & $\begin{array}{l}\text { A:HOH732:O- } \\
\text { UNK0:O }\end{array}$ & 2.8020 & Su H-Bağ1 & A:HOH732:O & UNK0:O & $\begin{array}{l}\text { O-Donör } \rightarrow \text { O- } \\
\text { Akseptör }\end{array}$ \\
\hline $\mathrm{X}-4 \mathrm{YNU}$ & $\begin{array}{l}\text { A:HOH1046:O- } \\
\text { UNK0:O }\end{array}$ & 3.2804 & Su H-Bağ1 & A:HOH1046:O & UNK0:O & $\begin{array}{l}\text { O-Donör } \rightarrow \text { O- } \\
\text { Akseptör }\end{array}$ \\
\hline
\end{tabular}




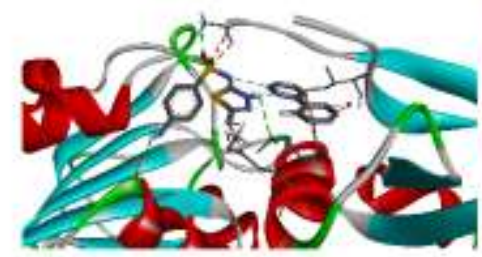

(a)

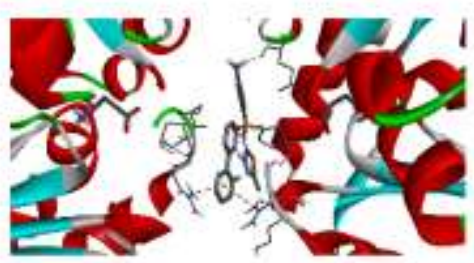

(d)

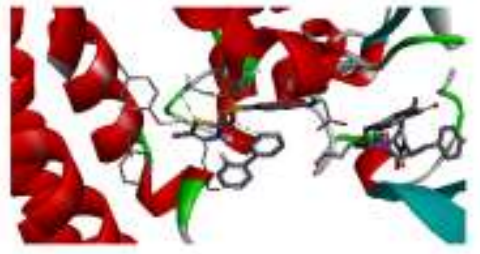

(b)

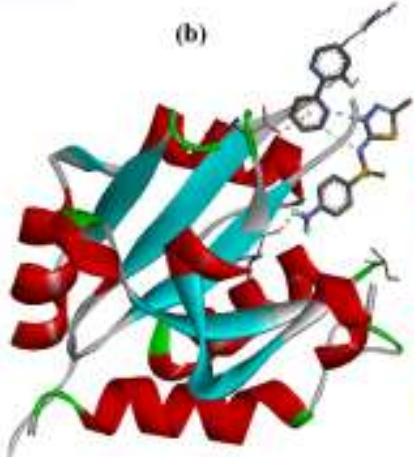

(e)

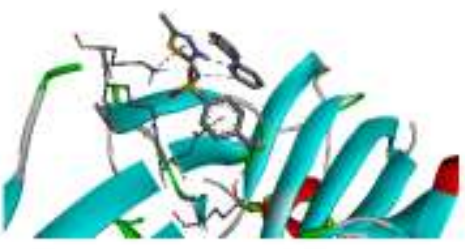

(c)

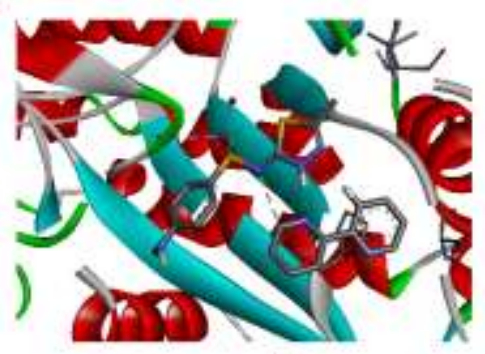

(f)

Şekil 11. Kompleksin (a) 5J9B, (b) 5BMM, (c) 5HTG, (d) 1ZUV, (e) 4F0V ve (f) 4YNU proteinlerle etkileşimi

Tablo 8, kompleksin proteine bağlandığında meydana gelen etkileşim enerjilerini ve protein için etkileşimli enerji düzeninin $5 \mathrm{HTG}>4 \mathrm{~F} 0 \mathrm{~V}>5 \mathrm{BMM}>4 \mathrm{YNU}>5 \mathrm{~J} 9 \mathrm{~B}>1 \mathrm{ZUV}$ olduğunu göstermektedir. Moleküler yerleştirme sonucuna göre 5HTG, 4F0V, 5BMM, 4YNU, 5J9B ve $1 \mathrm{ZUV}$ için inhibisyon sabitleri sırası ile $0.680,7.256,28.056,0.575,14.268,4.369 \mu \mathrm{M}$ olarak hesaplanmıştır. İnhibisyon sabiti bir ligandın bir enzimi inhibe edeceğini ve enzim için bir substratla etkileşime girebileceğini öngören bilgiyi sağlar. İnhibisyon sabiti aynı zamanda proteine ligandın bağlanma afinitesinin bir ölçüsüdür. Genel olarak, yüksek afiniteli ligand bağlanması, ligand ve reseptörü arasındaki daha büyük moleküller arası kuvvetten kaynaklanırken, düşük afiniteli ligand bağlanması, ligand ve bunun reseptörü arasında daha az moleküller arası kuvvet içerir. $\mathrm{K}_{\mathrm{i}}$ konsantrasyonu düştükçe, bekleyen iyon ile alıcı antijen arasında kimyasal bir reaksiyon oluşma olasılığı artar. Düşük afiniteli bağlanma (yüksek $\mathrm{K}_{\mathrm{i}}$ seviyesi), bağlanma bölgesi en fazla işgal edilmeden ve bağa maksimum fizyolojik yanıt alınmadan önce nispeten yüksek bir ligand konsantrasyonunun gerekli olduğu anlamına gelir. Yani, inhibisyon sabiti ne kadar küçükse enzim aktivitesini inhibe etmek için o kadar az ilaca ihtiyaç duyulur [31]. Buna göre Staphylococcus aerous ve Bacillus Subtilis bakterilerine karşı daha az kompleks-ilaçtan alınabileceği söylenebilir.

Tablo 8. Bahsedilen proteinler için $\Delta G_{B}$ ve $\mathrm{K}_{\mathrm{i}}$ değerleri

\begin{tabular}{lll}
\hline Protein ID & Serbest Bağlanma Enerjisi $\Delta G_{B}(\mathrm{kcal} / \mathrm{mol})$ & İnhibisyon Sabiti, $\mathrm{K}_{\mathrm{i}}(\mu \mathrm{M})$ \\
\hline 5J9B & -8.4 & 0.680 \\
5BMM & -7.0 & 7.256 \\
5HTG & -6.2 & 28.056 \\
1ZUV & -8.5 & 0.575 \\
4F0V & -6.6 & 14.268 \\
4YNU & -7.3 & 4.369 \\
\hline
\end{tabular}

\section{Sonuç ve Öneriler}

Sülfonamid grubu ilaç etken maddelerden olan sülfametiyazol en önemlilerinden biridir. Öncelik ile sülfametiyazolün (Hsmtz)-2,2'-bipiridin (bipy) tuzunun sentezi yapıldı. Elde edilen kristallerin X-1şını kırınımı sonucunda kompleksin asimetrik biriminde bir sülfametiyazol molekülü ve bir 2,2'-bipiridin molekülü içerdiği görüldü. Sülfametiyazolün sülfonamido bölümündeki protonu amino formunda iken, kompleks oluşumunda tiyadiazol halkasındaki azot atomuna bağlanarak imido formunda olduğu görülmüştür. 
Yapılan IR spektral analiz sonucunda kristal oluşumu sonucunda sülfametiyazolün imido formunda olduğu göz önüne alındığında elde edilen deneysel değerlerin, literatür ve teorik hesaplama sonuçları ile oldukça uyumlu olduğu görülmektedir. Gözlenen küçük farklılıkların ise gaz fazındaki yok sayılan moleküler etkileşimlerden kaynaklandığı bilinmektedir. Antibakteriyel çalışması neticesinde kokristalin Staphylococcus aureus, Bacillus subtilis, Pseudomonas aeruginosa ve Candida albicans suşlarına karşı bir etki göstermez iken, Escherichia coli ve Aspergillus flavus suşlarına karş1 etki gösterdiği sonucuna varılmıştır.

Buna ilaveten optimize edilen kompleks sonuçları kullanılarak Protein Data Bank'tan (http://www.rcsb.org/pdb/home/home.do) alınan 5J9B, 1ZUV, 5BMM, 4F0V, 5HTG ve 4YNU ID kodlu proteinlere yerleştirildi. Proteinin aktif bölgeleri ile kompleks hidrojen bağları ve zayıf etkileşimler yaparak, biyolojik aktivitesi teorik olarak incelendi. İnceleme sonucunda kompleksin tüm proteinler ile baskın olarak hidrojen bağı yaparak etkileşim gösterdiği gözlenmiştir. Kompleksin proteine bağlandığında meydana gelen etkileşimi sonucunda inhibisyon sabitlerinin elde edilmesi ile kompleks-ilacın hangi tür protein ile ne kadar etkileyeceği hakkında bilgi edinebilmemizi sağlamıştır.

\section{Ek Materyal}

Bu çalışma için CCDC No: 1909805 ek kristalografik verileri içerir. Bu veri http://www.ccdc.cam.ac.uk/ adresinden ücretsiz olarak elde edilebilir.

\section{Yazarların Katkısı}

Yayında Giriş, sentez kısmını Filiz ÖZTÜRK, Kimyasal hesaplamalar ve termal analiz ile ilgili bölümler Tugba AYCAN tarafindan hazırlanmıştır. Antimikrobiyal analiz ise Ahmet Hilmi ÇON tarafından yapılmıştır. Bunların dışında kalan bölümler ise Filiz ÖZTÜRK ve Tuğba AYCAN'ın birlikte yapmış olduğu ve tamamlanmış bir çalışmadır.

\section{Çıkar Çatışması Beyanı}

Yazarlar arasında herhangi bir çıkar çatışması bulunmamaktadır.

\section{Araştırma ve Yayın Etiği Beyanı}

Makale araştırma ve yayın etiğine uygun bir şekilde hazırlanmıştır.

\section{Kaynaklar}

[1] Toth J.E., Grindey G.B., Ehlhardt W.J., Ray J.E., Boder G.B., Bewley J.R., Klingerman K.K., Gates S.B., Rinzel S.M., Schultz R.M. 1997. Sulfonimidamide Analogs of Oncolytic Sulfonylureas. Journal of medicinal chemistry, 40 (6): 1018-1025.

[2] Medina J.C., Roche D., Shan B., Learned R.M., Frankmoelle W.P., Clark D.L., Rosen T., Jaen J.C. 1999. Novel halogenated sulfonamides inhibit the growth of multidrug resistant MCF-7/ADR cancer cells. Bioorganic \& medicinal chemistry letters, 9 (13): 1843-1846.

[3] Northey E.H., Litchfield J.T., White H.J. 1948. Sulfonamides and allied compounds. American Chemical Society monograph, Reinhold Publishing Co., New York, NY.

[4] Rall T. 1990. The Pharmacological Basis of Therapeutics. 8th edn.(Gilman, AG; Rall, TW; Nies, AS; Taylor, P. ed.), Perfamon Press. New York.

[5] Irvine A.D., Hoeger P.D.P.H., Yan A.C. 2011. Harper's Textbook of Pediatric Dermatology. Wiley.

[6] Bjerrum L., Dessau R.B., Hallas J. 2002. Treatment failures after antibiotic therapy of uncomplicated urinary tract infections. A prescription database study. Scandinavian journal of primary health care, 20 (2): 97-101.

[7] Bjerrum L., Gahrn-Hansen B., Grinsted P. 2009. Pivmecillinam versus sulfamethizole for shortterm treatment of uncomplicated acute cystitis in general practice: a randomized controlled trial. Scandinavian journal of primary health care, 27 (1): 6-11. 
[8] Suzuki T., Yamamoto Y., Abe K., Hirano M., Oka H. 1999. Sulfamethizole capsules containing contrast medium for assessment of gastric emptying in functional dyspepsia patients. Digestive diseases and sciences, 44(9): 1741-1746.

[9] Chourasiya S.S., Patel D.R., Nagaraja C., Chakraborti A.K., Bharatam P.V. 2017. Sulfonamide vs. sulfonimide: tautomerism and electronic structure analysis of N-heterocyclic arenesulfonamides. New Journal of Chemistry, 41(16): 8118-8129.

[10] Suresh K., Minkov V.S., Namila K.K., Derevyannikova E., Losev E., Nangia A., Boldyreva E.V. 2015. Novel synthons in sulfamethizole cocrystals: structure-property relations and solubility. Crystal Growth \& Design, 15 (7): 3498-3510.

[11] Duggirala N.K., Perry M.L., Almarsson Ö., Zaworotko M.J. 2016. Pharmaceutical cocrystals: along the path to improved medicines. Chemical Communications, 52 (4): 640-655.

[12] Stoe C. 2002. X-AREA (Version 1.18) and X-RED (Version 1.04), Stoe \& Cie, Darmstadt, Germany.

[13] Burla M.C., Camalli M., Carrozzini B., Cascarano G.L., Giacovazzo C., Polidori G., Spagna R. 1999. SIR99, a program for the automatic solution of small and large crystal structures. Acta Crystallographica Section A: Foundations of Crystallography, 55 (6): 991-999.

[14] Sheldrick G.M. 2015. Crystal structure refinement with SHELXL. Acta Crystallogr C Struct Chem, 71(Pt 1): 3-8.

[15] Frisch M., Trucks G., Schlegel H.B., Scuseria G., Robb M., Cheeseman J., Scalmani G., Barone V., Mennucci B., Petersson G. 2009. Gaussian 09, revision a. 02, gaussian, Inc., Wallingford, CT, 200.

[16] Trott O., Olson A.J. 2010. AutoDock Vina: improving the speed and accuracy of docking with a new scoring function, efficient optimization, and multithreading. Journal of computational chemistry, 31 (2): 455-461.

[17] BIOVIA D.S., BIOVIA Discovery Studio Visualizer, v16. 1.0. 15350, San Diego: Dassault Systemes; 2015 [cited: 2017 Mar 20].

[18] Öztürk F., Bulut İ., Yavuz Y., Bulut A. 2016. Sulfamethizole-2-amino-4, 6-dimethoxypyrimidine (1/1). IUCrData, 1 (6): x161030.

[19] Öztürk F., Bulut İ., Bulut A. 2015. Structural, spectroscopic, magnetic and electrochemical studies of monomer N-substituted-sulfanilamide copper (II) complex with 2, 2'-bipyridine. Spectrochimica Acta Part A: Molecular and Biomolecular Spectroscopy, 138: 891-899.

[20] Vega-Hissi E.G., Andrada M.F., Zamarbide G.N., Estrada M.R., Tomás-Vert F. 2011. Theoretical studies on sulfanilamide and derivatives with antibacterial activity: conformational and electronic analysis. Journal of molecular modeling, 17 (6): 1317-1323.

[21] Das D., Sahu N., Roy S., Dutta P., Mondal S., Torres E.L., Sinha C. 2015. The crystal structure of sulfamethoxazole, interaction with DNA, DFT calculation, and molecular docking studies. Spectrochimica Acta Part A: Molecular and Biomolecular Spectroscopy, 137: 560-568.

[22] Merrick J.P., Moran D., Radom L. 2006. An Evaluation of Harmonic Vibrational Frequency Scale Factors. J. Phys. Chem., A 111: 11683-11700.

[23] Jarzqcki A.A., Kozlowski P.M., Pulay P., Ye B.H., Li X.Y. 1997. Scaled quantum mechanical and experimental vibrational spectra of magnesium and zinc porphyrins. Spectrochimic Acta Part A, 53: 1195-1209.

[24] Yamamoto L.M., Nunes J.H.B., Ribeiro M.A., da Costa Ferreira A.M., Lustri W.R., Corbi P.P. 2017. Copper (II) and silver (I) complexes with sulfamethizole: synthesis, spectroscopic characterization, ESI-QTOF mass spectrometric analysis, crystal structure and antibacterial activities. Polyhedron, 138: 168-176.

[25] Hossain G.G., Amoroso A., Banu A., Malik K. 2007. Syntheses and characterisation of mercury complexes of sulfadiazine, sulfamerazine and sulfamethazine. Polyhedron, 26 (5): 967-974.

[26] Padmaja L., Amalanathan M., Ravikumar C., Joe I.H. 2009. NBO analysis and vibrational spectra of 2, 6-bis (p-methyl benzylidene cyclohexanone) using density functional theory. Spectrochimica Acta Part A: Molecular and Biomolecular Spectroscopy, 74 (2): 349-356.

[27] Obayes H.R., Al-Amiery A.A., Alwan G.H., Abdullah T.A., Kadhum A.A.H., Mohamad A.B. 2017. Sulphonamides as corrosion inhibitor: Experimental and DFT studies. Journal of Molecular Structure, 1138: 27-34. 
[28] O'boyle N.M., Tenderholt A.L., Langner K.M. 2008. Cclib: a library for package-independent computational chemistry algorithms. Journal of computational chemistry, 29 (5): 839-845.

[29] Polishchuk A.V., Karaseva E.T., Emelina T.B., Cramariuc O., Karasev V.E. 2011. Polymorphism and Intramolecular Proton Transfer in Fluoroquinolone Compounds. Journal of fluorescence, 21 (6): 2117.

[30] Ayankojo A.G., Tretjakov A., Reut J., Boroznjak R., Öpik A., Rappich J., Furchner A., Karsten H., Syritski V. 2016. Molecularly Imprinted Polymer Integrated with a Surface Acoustic Wave Technique for Detection of Sulfamethizole. Anal. Chem., 882: 1476-1484.

[31] Sayin K., Karakaş D., Kariper S.E., Sayin T.A. 2018. Computational study of some fluoroquinolones: Structural, spectral and docking investigations. Journal of Molecular Structure, 1156: $172-181$. 